\title{
Osman Bayder. El-Hidâye: Bir Fıkıh Metninin Hanefî Geleneğe Etkisi. İstanbul: Hacıveyiszade İlim ve Kültür Vakfı Yayınları, 2020, 195 sayfa.
}

\begin{abstract}
Abdullah BARDAKCI ${ }^{*}$
Klasik eserlerle olan irtibatımız arttıkça klasiklerin nasıl klasikleştiği konusuna olan ilgi ve merakımız da derinleşiyor. Özellikle Hanefî fıkıh literatürünün klasik hüviyetini kazanmış bazı örnekleri, sâir kitaplardan daha fazla ilgi görmüş, birçok çalışmaya konu olmuştur. Mâverâünnehir bölgesi fakihlerinden Ali b. Ebî Bekir el-Merğînânînin (ö. 593/1197) el-Hidâye şerhu Bidâyeti'l-mübtedî isimli eseri de üzerine şerh, haşiye, ta'lîk türlerinde yüzün üzerinde çalışma yapılmış bir klasiktir. Osman Bayder, el-Hidâye: Bir Fıkıh Metninin Hanefî Geleneğe Etkisi adlı kitabında Merğînânînnin meşhur eserinin kendinden sonraki Hanefî geleneğe etkisini incelemektedir. Kitap üç bölümden oluşmaktadır. Kitaptaki yol haritasını ve izlenen yöntemi bölümler özelinde açıklayan detaylı bir giriş bölümü barındırmayan eserin “Öz Söz”ünde yazar, kitaptaki hedefini ve kitabın inceleme alanını şöyle belirtmiştir: “Bu çalışma Hidâye’nin Hanefî literatürü açısından önemini ve sonraki döneme etkisini incelemektedir” (s. 8). Birinci Bölüm'de standart bir âlim biyografisinin aktarımı yerine Merğînânînin yer aldığ gelenekten, içinde bulunduğu ilmî çevreden bahsedilmiş ve mezhep içindeki konumu ile içtihat derecesi tartışılmıştır. Bu bölümde müellifin hayatına dair kitabın iddiasını desteklemeyecek bilgilerin bulunmaması kitap için artı olsa da Merğînânî̀ye ait eserlerin tamamının burada verilmemesi eksiklik olarak değerlendirilebilir. Ayrıca bazı eserlerin zikredildiği yerde Merğînânînin Muhtârâtü'n-nevâzil isimli eseri sehven Muhtârâtu'z-Ziyâdât olarak verilmiştir (s. 19). Zira kaynaklarda Merğînânîye böyle bir eser nispet edilmemektedir. Yazar bu bölümde, Merğînânînin Hanefî füru fikhı açısından konumunu tartıştıktan sonra onun mezhebin usulündeki önemini de önemli usul ve kelam kitaplarının aktarım silsilelerini inceleyerek göstermeye çalışmıştır.

Kitabını genel bir bakışla, Birinci Bölüm’de Merğînânî, İkinci Bölüm’de Hidâye, Üçüncü Bölüm'de de Hidâye’nin geleneğe etkisi olarak bölümlendiren yazar, İkinci Bölüm'de Hidâye’nin Hanefî literatüründe nerede durduğunun tespiti için bu literatürdeki farklı tasnifleri değerlendirmiştir. Bu bağlamda metin-şerh-fetâvâ ayrımını inceleyip metin kavramına giren eserler ile bu eserlerin temel özelliklerini tespit etmeye çalışmıştır. Sonrasında Hidâye'nin

* Arş. Gör., İstanbul Medeniyet Üniversitesi Hukuk Fakültesi İslam Hukuku Anabilim Dalı. abdullah.bardakci@ medeniyet.edu.tr

ORCID: 0000-0002-1876-6595
\end{abstract}


metinsel özelliklerini, tertibini ve kaynaklarını irdelemiş, Hidâye’nin üzerine yazıldığı $B i$ dâye ile Kudûrînin (ö. 428/1037) Muhtasar'ını karşılaştırmıştır. Ayrıca Bidâye metnine kaynak olarak el-Câmi 'u'l-kebîr'in değil de el-Câmi 'u's-sağîr' in tercih edilmesinin muhtemel sebepleri üzerinde durmuştur.

Kitabın asıl amacının temellendirilmesini oluşturan Üçüncü Bölüm'de yazar, Hidâye şârihlerinin eser hakkındaki görüşlerinden başlayarak Merğînânî sonrası Hanefî gelenekte $\mathrm{Hi}$ dâye’nin etkisi ve önemini göstermeye çalışmaktadır. Yazar, Hidâye’nin etkisini, medreselerde çok okutulması, üzerine çok çalışma yapılması, tercihlerinin sonraki eserlerde ve kaza ve fetvada tercih edilmesi üzerinden incelemektedir. Bundan sonra Hidâye’nin Hanefî coğrafyadaki (Irak-Şam-Mısır-Anadolu ve Hint bölgesi) seyrini, ilmi çevrelerde dolaşımını, Merğînânînin öğrencileri ve bölgelerde Hidâye üzerine yazılan ilk eserler ve yazarları hakkında bilgi vererek ele almıştır. Son olarak Hidâye etrafında şekillenen literatürü ilk örneklerinden başlayarak veren ve değerlendiren yazar, "ehl-i hadis eğilimli Hanefîler"in Hidâye üzerine yazdıkları eserlerden Hanefî çevrelerdeki hadise yaklaşım farklarını göstermeye ve açıklamaya çalışmıştır. Kitap, yapılan çalışmanın hasılasını ifade eden bir bölümden ziyade, önceki bölümlerin özetini içeren kısa sonuç bölümünün ardından Hidâye üzerine yapılmış çalışmaların listesini içeren ve Merğînânîden gelen Hanefî geleneği gösteren tabloyla tamamlanmaktadır.

Yazarın, Öz Söz'de kitabında izleyeceği yolu ve metodu ayrıntılı olarak açıklamaması ve bölümlerin birbiriyle ilişkisini açıkça ortaya koymaması, bölümler arası bir kopukluk hissine sebep olmuştur. Bölümlerin amaçlarının kitabın ana amacını nasıl desteklediği yazar tarafından daha net ifadelerle verilseydi, kitabın tezi daha güçlü bir şekilde aktarılabilirdi.

Birinci Bölüm’de, tekrarlana gelen tarihî bilgiler yerine Merğînânînin ilmî çevresi hakkında malumat verilmiş olsa da Hidâyẻnin yazıldığı dönemin ilmî muhiti ve Mâverâünnehir fukahası hakkında yeterli arka plan bilgisi sunulmamıştır. Zira bu bölgenin âlimlerinden olan Merğînânî, eserini de kendisinden önce gelenek oluşturmuş bir muhite yönelik yazmıştır. Bu bağlamda, Merğînânînin hoca-talebe ilişkileri kadar, Hidâye’nin yazıldığı ortam ve o ortamın fikhi işleyişi de eserin ve müellifin anlaşılması için önem arz etmektedir. Ayrıca, metin ve şerhlerin, Mâverâünnehir Hanefîliğìnde ve bölge eğitim geleneğinde hangi aşamalarda ve hangi işlevleriyle kullanıldığı daha net verilerle ortaya konulsaydı, Hidâye’nin yazılış amacı daha iyi anlaşılabilirdi.

Eserde Merğînânînin içtihat derecesi meselesi, İbn Kemal Paşa’nın (ö. 940/1534) Tabakâtü'l-fukahâ’sındaki tasnifi etrafında gelişen tartışmalar, taraflar ve tarafların gerekçeleri ile ilk eleştirileri hedef alan eleştiriler de eklenerek zengin bir muhtevayla ortaya konulmuştur. Bu tartışma neticesinde, aynı zamanda İbn Kemal Paşảnın fukaha tasnifinin de nasıl anlaşılması gerektiğini ortaya koyacak bir biçimde, Merğînânînin içtihat derecesi/mezhep fukahası içindeki yeri tartışılmıştır. Buna göre İbn Kemal Paşa fukahayı tabakalara ayırırken onların kendi fikhi yeteneğine/seviyesine göre değil, mezhep içinde öne çıktıkları 
özelliklerine göre sınıflandırmıştır. Merğînânî mezhepte, özellikle Hidâye’deki tercihleriyle ön plana çıtığ 1 için ashâbü’t-tercih tabakasında yer almıştır (s. 31). Bu bölüm hem İbn Kemal Paşan̉nın tasnifinin hem de Merğînânînin mezhep içindeki rolünün anlaşılması bakımından önemli tespitler içermektedir. Ayrıca yazar, Usûlüll-Pezdevî şârihlerinin verdiği rivayet silsilelerini ve Mâtürîdî gelenekte önemli bazı akaid/kelam eserlerinin rivayet silsilelerini incelemiş ve önemli usulcülerin arasında Merğînânînnin de yer aldığını tespit edip bunları kitapta göstermiştir. Yazarın, fürû fikıhtaki eseri ve etkisiyle bilinen bir âlimin, mezhebin usulü açısından önemine işaret etmesi, Merğînânînin usul birikiminin anlaşılması noktasinda önem arz etmektedir.

Yazarın İkinci Bölüm'de metin-şerh-fetâvâ ayrımına değinmesi Hidâye’nin konumu açısindan yerinde bir nokta olsa da aslında şerh olarak yazılan bu esere neden metin muamelesi yapıldığı açıllanmamaktadır. Zira yazar Merğînânı̂nin Hidâye'de yaptığı önemli şeylerin başında mezhep içi görüşlerin delil ve gerekçelerinin yer alması olduğunu sıkça tekrarlasa da (s. 7-8, 66, 74, 75, 87, 153) aslında gerekçelere yer verilmesi zaten şerhlerin genel bir özelliğidir. Ayrıca Hidâye, yazarın metinlerin özellikleri içinde zikrettiği "muhtasar olması" şartına da uymamaktadır. Bunlara rağmen Merğînânînin bu eserinin neden metin gibi muamele gördüğü sorusu kitapta cevaplanmamıştır.

Yazarın mezhepte muteber metinlerin temel özelliklerini verdiği kısımda serdetmiş olduğu özellikler metinlerin işlevlerinin anlaşılması açısından güzel bir deneme olsa da tenkite açık yönleri bulunmaktadır. Öncelikle yazar bu özellikleri belirlerken hangi metinleri esas aldığını açıç̧a belirtmemiştir. Eğer bu özellikler sonradan "dört metin" olarak adlandırılan eserler üzerinden yapıldıysa, ki bu ihsas edilmektedir (s. 61), bu tercihin gerekçesi verilmeliydi. Eğer böyle bir kriter yoksa, tüm muhtasar eserler/metinler aynı zamanda, aynı ortamda ve aynı amaçlar için yazılmış gibi sunulmuş olacaktır ki bu da ilgili türlerin tarihî süreçlerinin ihmal edildiği anlamına gelmektedir. Buna binaen yazar, standartlara uymayan ilk dönem muhtasarlarından ziyade mezhepte dört metin olarak adlandırılan metinler ile en-Nukâye, Gurer, Mültekâ gibi eserler üzerinden, serdetmiş olduğu özellikleri izah etmeye çalışmaktadır. Bu sebeple de metinlerin gerekçeleri barındırmamasından dolayı mezhebin entelektüel birikimini anlatma ve inceleme amacı gütmediği ifade edilmektedir (s. 64). Ancak yazarın daha önce belirttiği gibi, Tahâvî (ö. 321/933), Kerhî (ö. 340/952) ve Kudûrînin (ö. 428/1037) muhtasarları ile Hidâye bu anlamda sonraki metinlerden farklı özellikler barındırmaktadır (s. 60-1). Bu da en azından muhtasar literatürü için, tarihî süreçte bazı değişiklikler olduğuna işaret etmektedir. Yine bu düşüncenin bir sonucu olarak, eserde metinlerin asıl kitlesinin kadı ve müftüler olduğu belirtilmiş ve bu kesimlerin de belli bir dönemden sonra delile çok fazla ihtiyaç duymadığı söylenmiştir (s. 64-5). Yazarın bu iddiası belli bir dönemden sonrası için doğru olabilirse de bunun tüm Hanefî fikıh tarihine genellenmesi tartışmaya açıktır. Bununla birlikte, metinlerin kanunlaşma yolunda atılan adımlar olduğu (s. 59), bu metinlerin daha çok "kadı ve müftiler için standart görüş sunma" ve ilk basamak tedrisi amacı taşıdığı (s. 60) iddiaları da delillendirilmemiştir. Bu önemli iddiaların 
gerekçelendirilmeden, ön kabul şeklinde kitapta yer alması ve kitabın düşüncesine yön vermesi kitabın zayıf yönlerindendir. Zira yazar Hidâye’yi de bu öncüllerle anlamaya çalışmaktadır. Hâlbuki Üçüncü Bölüm’ün başında yazarın Hidâye şârihlerinden yaptığı alıntılar (s. 87-8, 90, 91) ve kitabın çeşitli yerlerinde Hidâye hakkında yapılan alıntılarda kazâ vurgusu hiç yer almamaktadır. Bu da en azından Hidâye için, metinlerin kazâdaki işlevinin yazarın tasvir ettiği derecede önemli olmadığını gösterir.

Hidâye'nin kaynaklarını incelediği bölümde yazar, Hidâye’nin kaynakları yerine Hidâye’nin metni olan Bidâye’nin kaynakları üzerinde durmuştur (s. 68-76). Hidâye'nin mezhep ve literatür içinde durduğu yer ve temsil ettiği birikimin anlaşılması açısından önemli olan bu bölümde, kitapta incelenen eserin kaynaklarının araştırılmamış olması önemli bir eksikliktir.

Kitabın ana amacını temellendirmeye imkân verecek olan Hidâye'nin tercihlerinin mezhepteki etkisine dair kısımda sadece dört örnek zikredilmekte (s. 94-6), ardından Hidâye tercihinin kabul edilmediği durumların bulunduğu belirtilmektedir. Ancak burada hem örnek sayısı azdır hem de verilen örneklerin ikisinde mezhep içinde Merğînânînin tercihi dışındaki görüşün de önemli metinlerde tercih edildiği ifade edilmiştir. Merğînânî ve Hidâye'nin en önemli özelliği olan tercih ve tashih faaliyetinin mezhebe etkisini ispat edecek önemli argümanlar bu kısım altında daha zengin bir muhtevayla verilebilirdi. Ancak ilgili örnekler kemiyet ve keyfiyet bakımından yetersizdir. Zira kitapta Hidâye'nin tercihleri ve Hidâye üzerine yazılan eserler dışında Hidâye’nin mezhep içindeki konumunu temellendirecek başka bir argüman bulunmamaktadır.

Yazarın Hidâye’nin nakli üzerinden gösterdiği seyir (s. 112-3) aynı zamanda Hanefîliğin, daha özelde Mâverâünnehir Hanefîliği’nin Anadolu’ya girişi konusuna da ş̧ık tutmaktadır. Ayrıca Hidâye'nin ulaştığı coğrafyalardaki hâkim fikıh anlayışını belirlemek amacıyla Hidâye şerhlerinin ve şârihlerin incelenmesi kitabın başarılı yönlerindendir. Yazar, Hidâye üzerine yapılmış hadis çalışmalarını da inceleyip Hanefî fukahadaki hadislere bakıştaki değişiklikleri ve sebeplerini de açıklamaya çalışmıştır. Bu bağlamda yazar, Ehl-i hadîse meyilli Hanefî fukahanın Hidâye'nin hadislerinin tahricini konu alan eserleri ile Hidâye'nin hadislerine yönelik eleştirilerini aktarmış ve özelde Mâverâünnehir fukahasının, genelde de erken dönem Hanefîlerin hadise bakış açılarını karşılaştırmıştır. Bu kısımda Hanefî fukahanın neden hadis kitaplarındaki sahih hadisleri kullanmadığı konusunu ve hadise bakış açılarını açıklayan yazar, Mâverâünnehir fukahası için ihticâca layık olan hadislerin fikıh kitaplarında nakledilen hadisler olduğu, bundan dolayı meşhur hadis kitaplarını önemli muhaddislerden okuyan Merğînânînin kitabında Ehl-i hadis kriterlerine göre zayıf olan hadisler yer alabileceğini belirtmiştir. Merğînânînin hadislerinin de çoğunlukla Serahsîden olduğunu ifade eden yazarın (s. 149-51) bu tespitleri erken dönem ve Mâverâünnehir Hanefîliği’nin hadise yaklaşımının ortaya konulması ve Memlük dönemi Hanefîlerinin değişen tavrının anlaşılması için önem arz etmektedir. 
Yazarın sonuç bölümünde Hanefî literatürünün ilk sistematik metni olarak Kudûrînin Muhtasar'ını ve ikinci olarak da Hidâye'yi zikretmesinin (s. 153) sebebi açık değildir. Zira yazarın sistematiklik ifadesiyle neyi kastettiği belirsizdir. Kudûrî öncesinde de önemli muhtasarlar yazıldığı ve Hidâye’nin, Kudûrînin Muhtasar’’nı kaynak almış bir metnin şerhi olduğu dikkate alındığında bu sıralamada Hidâye’nin ikinci olarak anılması da ilginçtir.

Kitabın sonundaki Hidâye üzerine yapılan şerh/haşiye/ta'lîkler ve hadis çalı̧malarını içeren ekler ise Hidâye'nin gelenekteki etkisinin en somut göstergesidir. Ancak Hidâye üzerine yapılan çalışmalar daha önce zaten çalışılmıştı. ${ }^{1}$ Üçüncü ek ise Merğ̂̂nânî sonrası Hanefî geleneği daha çok Hidâye üzerine eser yazan yahut aktarımında bulunan kişiler özelinde sunduğu için başarılıdır. Ancak yazarın bu tabloyu ek olarak değil de Hidâye’nin dolaşımını anlattığı bölümden sonra koyması ve değerlendirmesi daha isabetli olabilirdi.

Eserde birincil kaynak kullanımı iyi bir düzeyde ise de ikincil literatür açısından durum böyle değildir. Türkçe ikincil literatürden yer yer yararlanılmış ancak daha önce bu konuda yazılanlar neredeyse hiç tahlil edilmemiştir. Arapça ve İngilizce ikincil literatürden istifade ise oldukça kısıtlıdır. Özellikle Mâverâünnehir coğrafyası ve erken dönem Hanefîliği üzerine yazılan ikincil literatürden yararlanılmamış olması önemli bir eksikliktir. Ayrıca eserde fetva adabına ilişkin değerlendirmelerin kaynağı büyük oranda İbn Âbidîn'dir (ö. 1252/1836). Fetvada yahut kazâda başka görüşlerin yahut Mâverâünnehir meşâyıhının fetva adabının farklı olabileceği çoğu kez değerlendirme dışı tutulmuştur.

Sonuç olarak eser klasikleşmiş bir metnin neden klasikleştiği gibi önemli bir soruyu temel alması açısından önem arz etmektedir. Bir klasiğin hangi özelliklerinden dolayı zamana meydan okuyup içinde bulunduğu literatürü etkilediğini anlamaya çalışmak, günümüzde klasiklerin nasıl okunması gerektiğiyle ilgili önemli bir probleme de ışılk tutacaktır. Kitabın alana bu açıdan katkısı olduğu söylenebilir. Ancak eserin girişte belirtilen, Hidâ$y e$ 'nin önemi, mezhep literatüründeki yeri ve geleneğe etkisini gösterme amacını başarılı bir şekilde yerine getirdiğini söylemek zordur. Ayrıca yazarın konuyu ve tartışmaları ileri düzeye taşıyacak yeni sorulara değinmemesi de bir eksikliktir. Bununla beraber kitabın, Merğînânînin mezhep içindeki konumunun ve Mâverâünnehir Hanefîliği ile Memlük/ Mısır Hanefîliğinin farklılıklarını Hidâye üzerinden göstermesi gibi yan sorular açısından başarılı olduğu söylenebilir.

1 Murat Şimşek, “Bir Hanefî Klasiği: Mergînânînin el-Hidaye’si ve Üzerine Yapılan Çalışmalar”, TALİD, 2014, sy. 23, s. 276-321. 